\title{
History vs. Reality, Mining industry diagnostic and environmental effects: Illustration case in real size of Tunisian mining basin
}

\author{
Karim Bensalem ${ }^{1}$ Mohsen Brahmi ${ }^{2}$ and Sonia Zouary ${ }^{3}$ \\ ${ }^{1}$ Research associate Economics Innovation, Versailles Saint-Quentin-en-Yvelines University, Sciences of \\ Environnement, Ile of France (SEIF), Jean Mutual Street Box. 2154. France. \\ ${ }^{2}$ Researcher affiliate Faculty of Economics and Management (FEMS), University of Sfax. Campus Zarruk \\ ISSAT. Glocette coullisse, Building $N^{\circ} 12$. \\ ${ }^{3}$ Department of Economics, Pr. of Universities, Higher Institute of Business Administration, HIBAS, Univeristy's \\ Complex, Center City Km.4. Univ. Sfax.
}

\begin{abstract}
The present paper's aim is to conduct a diagnosis of the real state of the Tunisian mining industry which is one of the main aisles of the Tunisian economy for over a century of activity, but does not hide, like all other mining developing countries, damage effects on the environment, society and human, despite the great effort of the authorities concerned. This descriptive study was based on graphs of mining land to reflect the really worrying environmental and economic situation concern the Tunisia mining south-west. Offering subsequently implemented strategies and future prospects for controlling the emission of dust and degradation of the plant community by supporting technological tools in this area, but remains a sensitive issue in the medium and long term, into these mining areas for its remarkable economic weight for the Tunisian economy.

Keywords: Tunisia, Mining Industry, damage, environmental, Future prospects.

JEL: Q25, Q51, Q53, Q54, Q55
\end{abstract}

Foreword : This paper is considered as summary of long study, but not completely, in Tunisian Mining areas Zone, witch has translated just a part of them from the original French article by author.

\section{Introduction}

Tunisian natural Phosphate $(\mathrm{P})^{1}$ is a sedimentary rock gray. It is characterized by a sandy texture and tender with a high internal porosity. Perspective of chemical structure, the phosphate rock has a microcrystalline structure belonging to the apatite family. Indeed, it is identified with a carbonated apatite fluoride. The latter is characterized by a highly substituted internal structure. The substitutions have occurred naturally in the crystal lattice of the lattice of apatite, by replacing ortho phosphate ions, $\mathrm{PO}_{4}{ }^{3-}$, by carbonate ions, $\mathrm{CO}_{3}{ }^{2-}$

This high substitution gives the ore a higher chemical reactivity. This made it can be brought in the rough ground, relatively acidic, dissolving in it and releasing phosphate ions needed by plants. It is considered, with nitrogen $(\mathrm{N})$ and potassium $(\mathrm{K})$, as a basic constituent of life of plants and animals. (FAO, 2009.2010)

Annual production ${ }^{2}$ of ore phosphate by the Company ${ }^{3}$ Public Tunisian Gafsa Phosphate is approximately 8.5 million tons / year (CPGT, December Echos 2011). A large proportion (75 to 80\% of annual production) of the ore is converted into phosphoric acid and fertilizers in various local factories of the Tunisian Chemical Group in Sfax and Gabes. The phosphate is mainly used for the manufacture of fertilizer for agriculture in high demand by industrial countries than those emerging, proving its high current (150 Euros / tone in October 2011) the last ${ }^{4}$ years the market world phosphate fertilizer, but also for other branches of chemical industry, particularly that of detergents.

However, despite his unique contribution to GDP of Tunisia, the industry of mining and recovery of mineral fertilizers does not hide these adverse effects on the environment, society and human health of the citizens of Tunisian Mining Basin.

1 In Tunisia, dated its discovery in 1897, the major phosphate accumulations are divided into three basins: the North Basin phosphate (RAAS El - Ouertane and Kalaâ-Khasba), the phosphate basin Center (Chérahil, Maknassy) and phosphate basin Southwest (Gafsa). These basins are one of the largest phosphate sets the world.

2 Tunisian Gafsa Phosphate 2 Echoes, period (1994-2011), National Statistics Institute, web link: www.ins.nat.tn, National Statistics Council, web link: www.tunisie-statistiques.tn

${ }^{3}$ State-owned Tunisian Gafsa Phosphate ranked third largest producer, web link: www.cpg.nat.tn .

${ }^{4}$ In 2008-2009, the price of the phosphate ore has sky rocketed in more than three times its average price (almost \$395/tonne, finally 2008) following the fluctuation of hydrocarbons and the application of phosphate fertilizers which does not cease to drop for the fertilization of agriculture. (FAO, 2009,2010 ) 


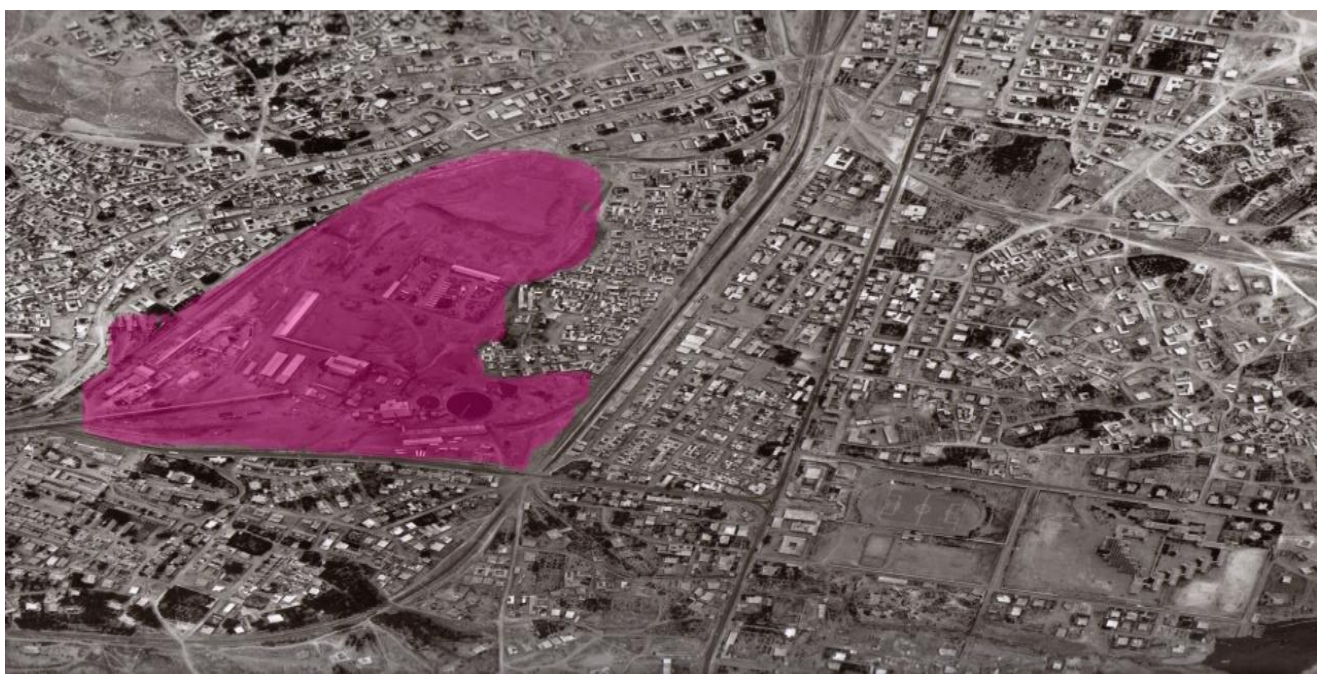

Figure1. Tunisian Mining (1901-2013): Area Zone of Mining Basin in urban areas of cities (Color illustration by the author).

Note: Effects author by color for appreciation on the mining area of the Tunisian Mining Basin.

Through this research paper we'll look primarily to present and analyze these negative effects caused by the mining industry. For this purpose, we conducted a descriptive diagnosis, based on graphs, on the real state of this Area Mining south-west.

Subsequently, we tried to identify some of these booms severe socio-economic and environmental concerns while exhibiting all of the strategies to implement, this mining industry in these areas rich in gray phosphate ore, but the poor through local and sustainable development.

\section{Diagnostic and the actual status of the Tunisian Mining Basin: Descriptive, analysis of the negative effects on the environment society and human.}

An overview, of the mining area Zone ${ }^{5}$, shows that the mining laundries have occupied a prime location in the heart of the city, affecting one hand, the aesthetic side and harmony of the whole and other hand side of the citizens' health and environment of this region.

This problem very difficult, without the real issues, remains today a question that must be managed in the coming years by the partial relocation of this industry toward the ends of the mining town, to minimize in a way, the emissions of the dust cleared, and the disposal of sludge phosphates after washing. (.cf, Figure. 2 below)

Figure 2. Location of the mining Laundries in the Center Urban City: Tunisia South-West.

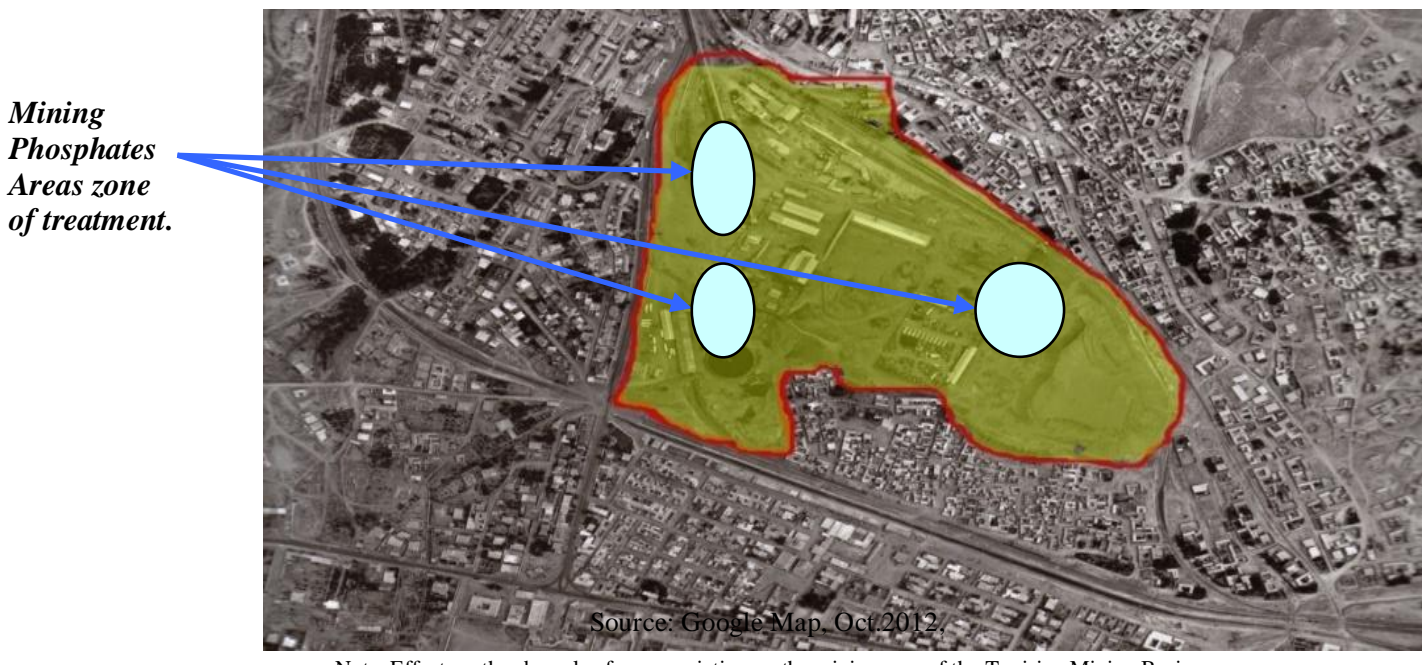

2.1 Mining industry in the heart of the mining town: Major threats

\footnotetext{
${ }^{5}$ We took th e case of the mining town 'Metaloui 'as framework for study which constitutes the greater pole of mining since more than a century of activity in this mining area in south of Tunisia.
} 
In order to introduce the main environmental and health problems which have suffered this mining region for several years, among the what, we will enumerate mainly the following points:

- threats affecting human health: the problems of dust issues very remarkable through the chemical damage covering the sky in this urban area, which have direct effects on the lungs and is unborn, accordingly, of new diseases affecting the respiratory tract of workers in this industry, although other touching the eyes very serious mining to citizens in general.

- The threats affecting the safety of cyclists (motorbikes and bicycles) and pedestrians: one of the remarks of passengers, in this space mining in the city center, this is the movement of large spacecraft enplanements of ores. These latter have causes including the serious accidents to the circulating in this main road in the center court of the mining town and which remains a difficult issue threatening, daily, the inhabitants of this region.

- Threats affecting the environment: remarkable exhaustion of the portable water for the phosphates ore washing, in against part, the rejection of mineral waste per channel in the arid areas zone, have caused the rise of mineral salts and the massive deterioration in the Oasis land and, consequently, the sudden disappearance of plant and animal species in this mining region, generally.

\subsection{Storage of the sterile phosphate: Phenomenon of dust}

The wind of sea" Elbahri", wind is Northeast, is also the main agent carrier of the sand with a frequency of $19.5 \%$ and a speed of up to $28 \mathrm{~m} / \mathrm{s}$. This wind makes from the spring life very painful. As well, with the presence of this stock of sterile phosphate exposed to all weather in the center mining town, without any protection, life is becoming more and more painful and seriously affects the health of the citizens of the Tunisian Mining Basin, who are heavily contaminated with these crowds of dust which invades all the urban space of this region south-west, without exception. (See figure. 3 below)

\section{Figure 3. Storage of mining phosphate sterile in a one of the greatest Tunisian mining areas zone: A massive} deterioration of the urban environment and the emergence of serious diseases to citizens

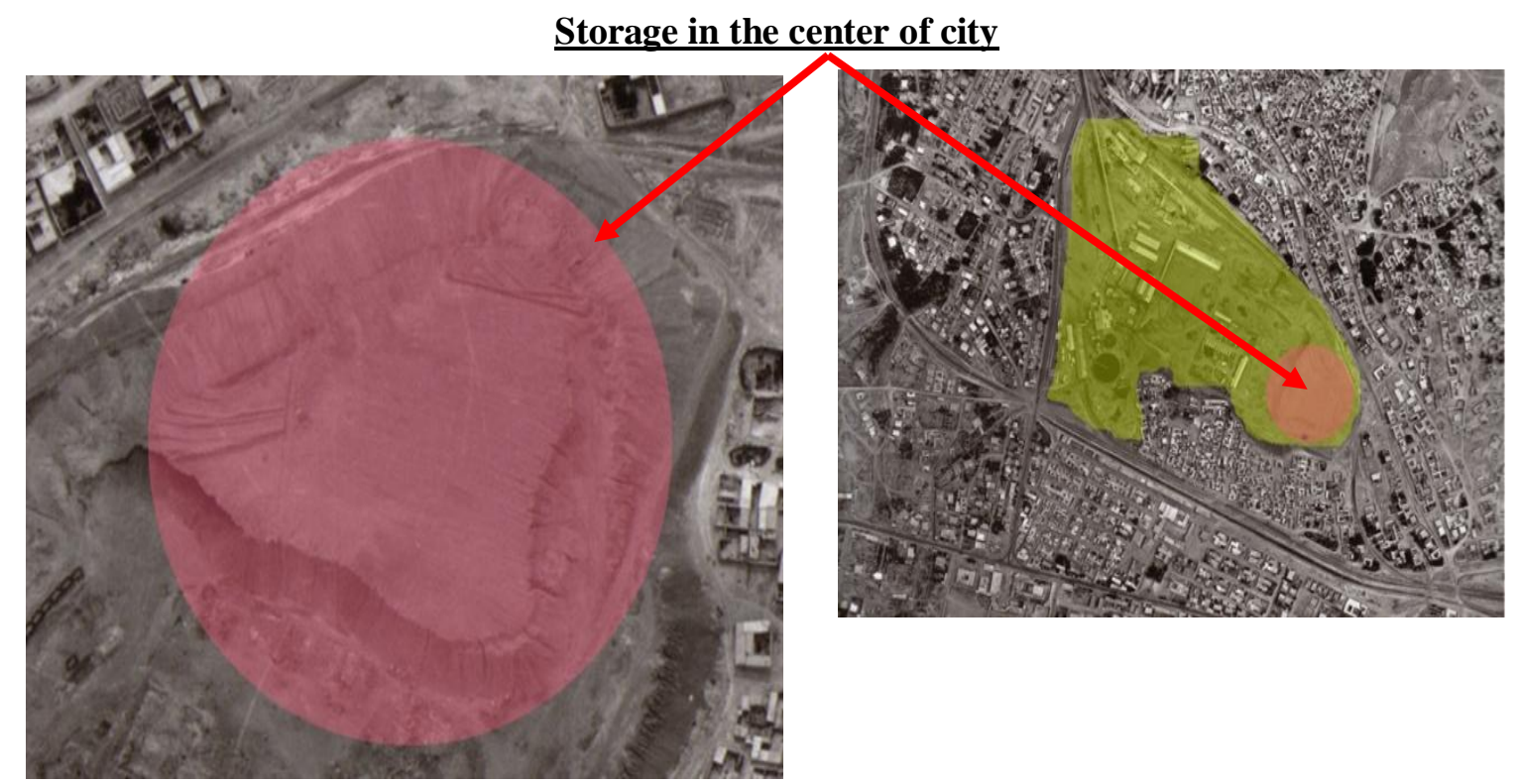

Source: Google Map, Dec 2012.

Note: Size enlargement and colors effect author's on the mining area of the Tunisian Mining areas.

\subsection{Disposal of thin phosphate sludge after treatment: Quantities rejected of discards}

The enrichment process by washing, which now replaces the process by ventilation, resulting in the production and the accumulation of small fine rejects in phosphate purposes. These releases are evacuated, in the form of water responsible for fine particles, called sludge, in some 'wadis' of the hydrographic system river of this mining areas region.

All these 'wadis', where are discharged its releases of sludge, which include the 'wadis Tarfaya', de 'Moulares', 'Tab-edit' and 'Thelja' for laundries of the mining areas in the north-west of Metlaoui, the 'wadis Chana Tarfaoui' and that of 'Djmel' all converge to 'El-guifla' in the 'oued Aouidia'. The latter, therefore receives the sludge of the whole of the laundries before to dump into the 'chott El-Gharsa' north, which is the final 
destination of accumulation of discards. The total annual discharge of sludge for ten laundries operated by the CPGT in the governorate of Gafsa is valued at $11 \mathrm{Mm}^{3} /$ year.

For, the period 2001-2020, the estimated qualities of discharges for laundries are probably as follows (D\&S Center, CPGT, and Dec.2011):

- Redeyef Laundries rejected : 270.000 tonnes/year

- Moularès Laundries rejected : 380.000 tonnes/year

- Métlaoui Laundries rejected : 710.000 tonnes/year

- M'dhila Laundries rejected : 200.000 tonnes/year

- S'ehib Laundries rejected : 410.000 tonnes/year

- Kef Eddour Laundries rejected : 530.000 tonnes/year

The flow of sludge rejected by the laundry of Kef Eddour is $600 \mathrm{~m} 3$. It dumps its sludge directly in the 'Oued Thelja', which vehicle also in Redeyef and de Moulares to 'Chott El-Gharsa'. The tableau.1, below, describes the quantities released during previous periods and their becoming in the hydrographic river.

All of the sludge rejected by the CPGT is discharged into the 'wadis' which are considered by the Tunisian regulations as part of the public domain hydraulic. The quality of these releases must, therefore, completely with the Tunisian standard mining chart $\mathrm{N}^{\circ} .5-106.002$ (1989). In addition, according to the law, $\mathrm{N}^{\circ} .88-91$ of the 2 August (1988), on the creation of a National Environmental Agency (ANPE), the CPGT is subject to the control of this agency and must meet its requirements in the fight against pollution.

Table 1. The quantities of ore mining processed in the laundries for the period (1979 / 2010) in tones:

\begin{tabular}{|c|c|c|c|c|l|}
\hline YEARS & METLAOUI & KEF EDOUR & MOULARES & REDAYEF & MDHILA \\
\hline $\mathbf{1 9 7 9}$ & 438531 & - & 69718 & 305233 & 813482 \\
\hline $\mathbf{1 9 8 0}$ & 452022 & - & 168081 & 668444 & 1288642 \\
\hline $\mathbf{1 9 8 1}$ & 584456 & - & 168081 & 755330 & 1507868 \\
\hline $\mathbf{1 9 8 2}$ & 573456 & - & 159343 & 780774 & 1562360 \\
\hline $\mathbf{1 9 8 3}$ & 574756 & - & 206831 & 780774 & 1562361 \\
\hline $\mathbf{1 9 8 4}$ & 623997 & 0 & 173682 & 620717 & 1418396 \\
\hline $\mathbf{1 9 9 4}$ & 500706 & 250597 & 267287 & 417829 & 1636468 \\
\hline $\mathbf{1 9 9 6}$ & 698153 & 407278 & 387146 & 568217 & 2267818 \\
\hline $\mathbf{2 0 0 0}$ & 712622 & 435678 & 353733 & 647998 & 2409606 \\
\hline $\mathbf{2 0 1 0}$ & 2654632 & 1697498 & 758624 & 1462498 & 3657148 \\
\hline
\end{tabular}

The Tunisian ore phosphate is treated in a dozen Laundromats located in the governorate of Gafsa. From 1998 to 2000, the cumulative amount of sludge rejected into 'wadis' has stabilized around 2.5 M Tones per year.

The results of analyzes of various samples collected during the decade (2000-2010), show their contribution to the accumulation of large tonnages of material in the clay beds and several 'wadis' at Delta 'Chot El-Gharsa' (3657148 tones in Mdhila and at lower accumulated in Kefedour, of 1,697,498 tones).The sludge generated by the laundries also provide of the sulfate, nitrate of chlorides and Phosphate remain absorbed on the deposits are a fine particles solid.

The result is a distribution of sludge rejected by the catchment basins of washing in the 'oued Aouidia', as presented in the table. 2, following both for the period (1979 / 2010), that for the annual (2009 / 2010) considered representative of the discards. The sludge and dropped in the hydrographic network river is applicant to around $90 \%$ outside the rainy phases resulting in important cures.

Table.2 Discharges purposes by river system (in tonnes)

\begin{tabular}{|l|c|c|}
\hline $\begin{array}{l}\text { TOTAL DISCHARGES FOR THE } \\
\text { PERIOD (1979/2010) }\end{array}$ & \% & TONES \\
\hline Oued Sebseb & 31.05 & 17131353 \\
\hline Oued Thelja & 48.25 & 35842154 \\
\hline Meleh et Jmel & 21.1 & 10542198 \\
\hline $\begin{array}{l}\text { Average annual of Discharges } \\
\text { (2009-2010) }\end{array}$ & - & 2048893,71 \\
\hline \multicolumn{2}{|l|}{ Source: D\&R, Search and prospection Direction, CPGT Jan.2010. Tunisie. }
\end{tabular}

Some quitter's spreader for the most part, to the first of the wadis, is object of the spill, such as the 'oued Sebseb' which has been the main destination for totals quitters found. Thus, due to its insufficient as hydrological vector, would have been the seat of the spreading of 17 million tons, approximately, distributed in a large area of natural spreading. 
The system 'Tabeddit-Tarfaia', which is part of the basin of Oued Thelja, has seen pass $35 \mathrm{M}$ tones, of which 7 $\mathrm{M}$ tones approximately would have applied to soils. Although, $21.1 \%$ of the discharges are passed, for the same period (1979/2010), in the shore of 'Meleh and Jmel', including nearly $10 \mathrm{M}$ tones at least.

In addition, under the effect of strong releases transmitted (48.25\%) to the 'Oued Thelja', this last has not supported the large quantities of discards, either 35842154 tones. Yet, the spreading of sludge has been able to make massively in this surface, where it causes a significant change in the morphology of the pad. This has product, gradually, a blatant enlargement of the area of the Oued, ranging from $500 \mathrm{~m}$ in 1979, which today has reached to $1.5 \mathrm{Km}$.

\section{Guidelines and set of strategies implemented:}

The basic orientation of confining the sludge in the sites, which at best can mitigate the environmental impact of these discharges, has been adopted two main branches which have been selected:

- The containment of sludge by spreading in the basins of containment.

- The containment of the sludge, previously thickened, tapered thickeners in deep.

On the spreading, the latter allows a greater consolidation of mud with a corollary reduction of volumes to confine. For such a process can practice for other mining wastes, an experimental phase is necessary to confine and possibly better adjust the size parameters in the basins of containment, as their power systems.

Concerning the thickening, the Tunisian Mining Company CPGT is already heavily engaged in such process by means of existing thickeners (CYCLARS) and has already reached a higher level of thickening on average than reached by most of the producers of phosphate in the world.

In the best cases, and with the current thickeners, the Mining Company has been able to achieve sometimes solid levels in excess of $400 \mathrm{~g} / \mathrm{L}$, levels of the same order of magnitude as those adopted, as average annual objective of the new generation called "thickeners deep tapered ".

However, the IFA ${ }^{6}$ on its part has edited two very useful technical repositories:

- Tea best Practice Technology (BPT): It is the best practice techniques that are based on technological improvements, likely to be implemented in the plants for the production of fertilizers.

- The Best Available Technology (BAT): This is a guide, who assumes the more sophisticated technologies and advanced, which are particularly useful for the constriction of the new plants less polluting, based on the experiences of the countries best classes in the mining industry.

Through the adaptation of these New Technologies (BPT and BAT), the International Agency of fertilization (IFA) was considered well the reduction of emissions of $\mathrm{CO}_{2}$ of $10 \%$ and $30 \%$, respectively, for these two New Technologies. It is a long-term scenario which is spread on any decade. (IFA, 2010).

In addition, the strategy of management of its releases purposes, to be put in place by the Tunisian Mining Company CPGT, would be based on the following principles:

- Schedule an experimental phase concerning two Laundromats in preference to low size, each equipped with according to a different track, to validate the evaluations chaff, and to refine the definition of final solutions.

- Introduce measures to control or mitigation of provisional for the other sites depending on the opportunities, these interim measures were expected to enroll in the framework of the final completion.

- Exercise a careful monitoring on the experimental development. This follow-up that will allow describing the final installations for the non-experimental sites.

- Predict a rapid action plan by the establishment of final installations for the largest Laundromats.

- Predict other from amenities, by the provision of New Technologies, so ensuring a more structural storage of liquid sludge in thick layers, if the recommended courses do not give the satisfaction technically and economically estimated.

Thus, two experimental facilities have been chosen for the experimental phase: (spreading of sludge liquids in thin for the site "Redeyef", storage of sludge under tower of rejection for the site of "Umm el Araies" after thickening).

The management facilities for this mining area in "Metlaoui" which is the most important, in terms of size, in the Mining Basin Tunisian, are:

- A conduct of rejection of sludge fonts with a length of $4.6 \mathrm{~km}$.

- A channel of sludge, linking the laundries toward the outside of the mining town, to a length of approximately $6 \mathrm{~km}$.

These developments lead the sludge of the laundries of Metlaoui, toward the area of 'SEBSEB', or the sludge rejected if apply on the right bank of 'oued SEBSEB'. This is the site of containment recommended. This area is currently the outfall discharges, already achieved over the past two decades.

\footnotetext{
${ }^{6}$ The International Agency of fertilization, IFA. 2010.
} 
This site of containment has the advantage of being formed by a spreading area already affected by sludge before the present project. Completion of the project will serve to confine the sludge which is currently apply in an erratic manner and to preserve the functionality of the hydrographic network river, in preserving the continuation of the sprays of sedimentations.

This containment project is established on a total surface area of the order of 1000ha. The upstream portion, either 257ha, has been chosen by the CPGT for planning. This site to be developed is in the form of two shores:

- The western boundary of the mining zone site is formed by a track non-appointed with a length of $3.4 \mathrm{~km}$ and direction north/north-east, south/south-east.

- The southern boundary of the mining areas site is formed by a track non-appointed with a length of $1.7 \mathrm{~km}$ and direction east $/$ north-east, south/west.

\section{Conclusion}

The primary idea, to mitigate the impact of the erosion and the dust of the urban environment of the Tunisian Mining Basin, already started since a few years ago, is to carry out an extensive program of implantation a tissue of trees which are adjusting well to the middle arid climate of this mining region of southwest (location of the fir trees at the top of the stock Phosphate and his entourage). The ultimate goal, firstly, to reduce the rate of dust released by the plants located in the center of this mining town, mistreated for more than fifty years.

Secondly, it is to foster a clean 'Green Zone 'covering the mining environment in full medium and long term, according to a predetermined forecast study (2002-2020). This plant tissue will, to some extent, to reduce the emission of $\mathrm{CO}_{2}$ gas and the radioactive ion phosphate and especially to oppose any act detrimental act to worsening health of residents of the Tunisian Mining Basin and the environment, in general.

However, these measures required by the executive authority in question are still less sufficient, until now, to save life on Earth (Human, plants and animals), in responding to damage caused by the mining industry sector added to new exploration mining, today, in this areas zone.

How, therefore, lead to a real adequacy between a green terrestrial environment and sustainable, in against bet, a polluting mining industry or even destructive? Question still outstanding and opens, soon, my next extensive research.

\section{Bibliographic References}

[1]. Annual reports of the Agency Fitch Ratings (2008, 2009, 2010, 2011).

[2]. Armiger.H and Fried. M., 1957, the plant availability of Various Sources of phosphate rock.

[3]. Armond, M, P., 1985, La Poussière des corons, 1985.

[4]. Blinker. L. R., 1997, Environnemental management of small-scale and artisanal mining sites in developing countries - Latin América and the Cariby region, UNEP IE/UNIDO Consultancy report.

[5]. Central Bank of Tunisia CBT, 2010, 51st annual report fiscal year 2009, Tunis, Tunisia,

[6]. Evolution of CPGT phosphate production in million tones, (2010-2012).

[7]. Echoes Tunisian Gafsa phosphate, period 1994-2010.

[8]. FAO, 2009, contributions from phosphate fertilizers in agriculture.

[9]. FAO, 2010, Fertilizer requirements in 2015 and 2030,

[10]. Hubermont, P., 1930, Treize homme dans la mine, paris, 1930.

[11]. IFA, 2009. world statistics by country,

[12]. IFA, 2009, Fertilizer, Climate change and enhancing agriculture productivity sustainably, 2009.

[13]. INS, 2010, Annual Report of exports of phosphate fertilizers

[14]. INS, 2011, Annual Report of imports mining.

[15]. International Fertilizer Industry Association I.F.A, 2010, Cartographies by Research group phosphate rock and Fertilizer Indu stry Association, USGS 2010.

[16]. Jasinski, S.M., 2010, Phosphate rock, U.S. Geological Survey Mineral Commodity Summaries 2010, 118-119.

[17]. Louis S., \& Jean-Claude B., 1982, La vie souterraine: les mines et les mineurs, Technology \& Engineering, 1982.324.

[18]. Ministry of Industry, Energy and of small medium enterprises, industrial modernization Plan and land use planning (2003-2007), 2008.

[19]. Zenaidi k., 1987, the global markets of phosphates and phosphate fertilizers, economica, 1978.

[20]. http://pollutionmetallique.zeblog.com/

[21]. http://www.atl.ec.gc.ca/epb/progs/mining_f.html

[22]. National Statistics Institute, web link: www.ins.nat.tn

[23]. National Statistics Council, web link: www.tunisie-statistiques.tn

[24]. Portal of Industry, Energy and small and medium enterprises, web link: www.industrie.gov.tn 


\section{ANNEXES}

Card1. Tunisian Mining Basin (1898-1900), composed: geographical map and urban of the mining region, first exploitation of mineral deposits.

Source: Data centre, Mining maps and archives, CPGT. 2012.

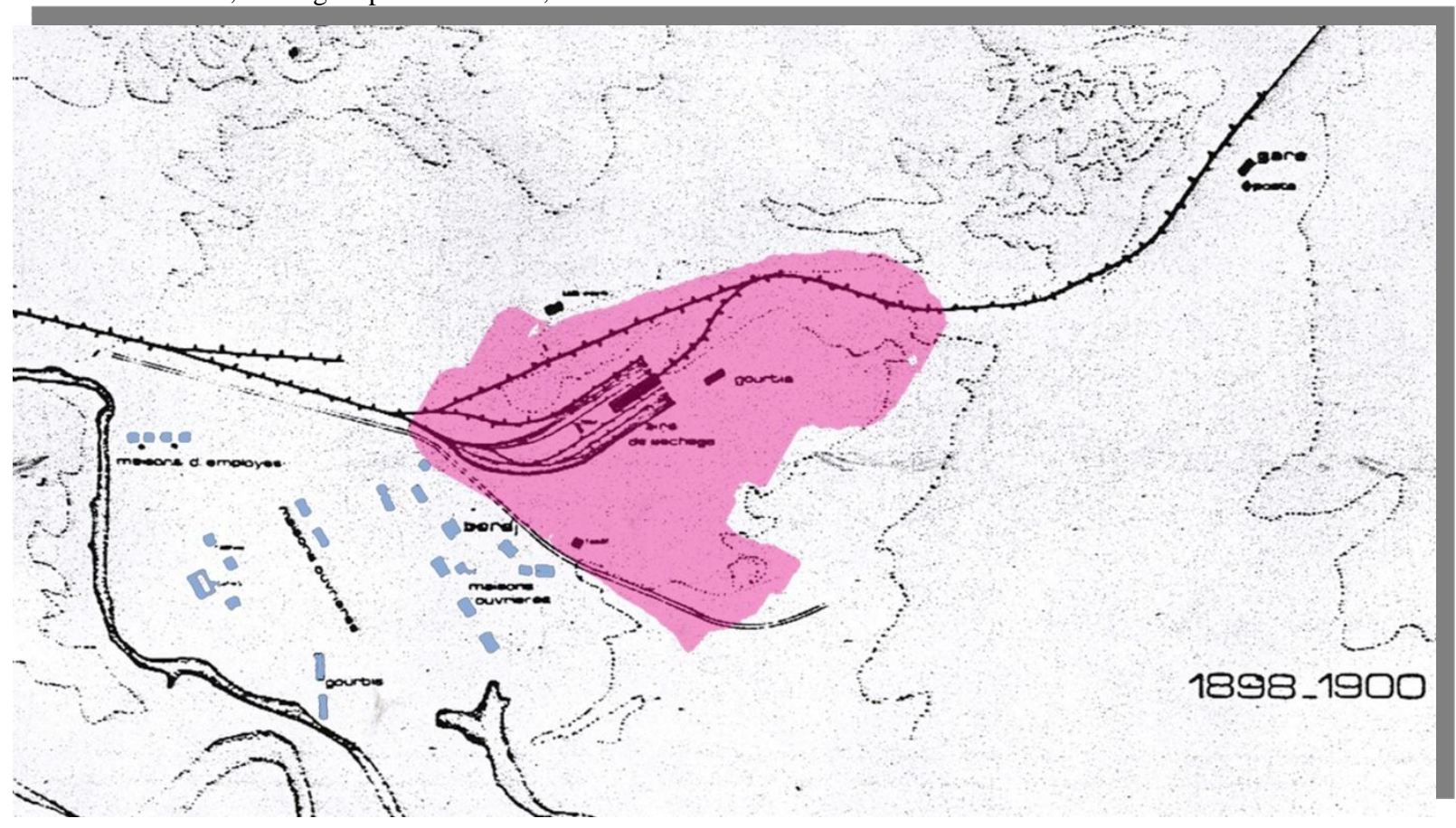

Card 2. THE SMALL PARIS: Topology of the situation with the installation on the side of the mining town of Tunisian workers: Extended urban, heterogeneous Conglomerate

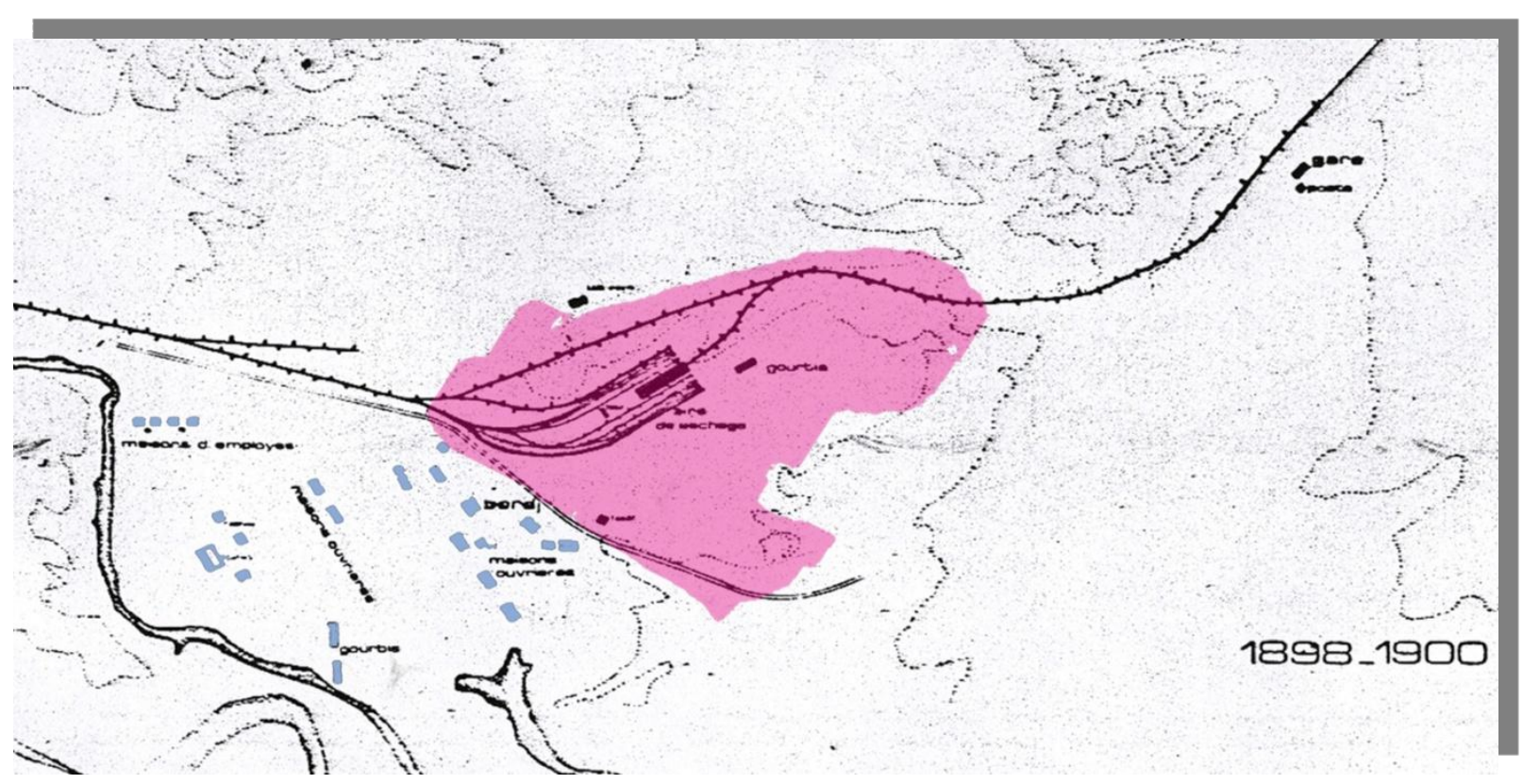

Source: Data centre, Mining maps and archives, CPGT. 2011.

Card 3. Illustrations of the effects following the European movements to the Tunisian Mining Basin (1910-1920): Equipment, Leisure at cited Urban Mining: Tools of cohabitation with the new environment. 


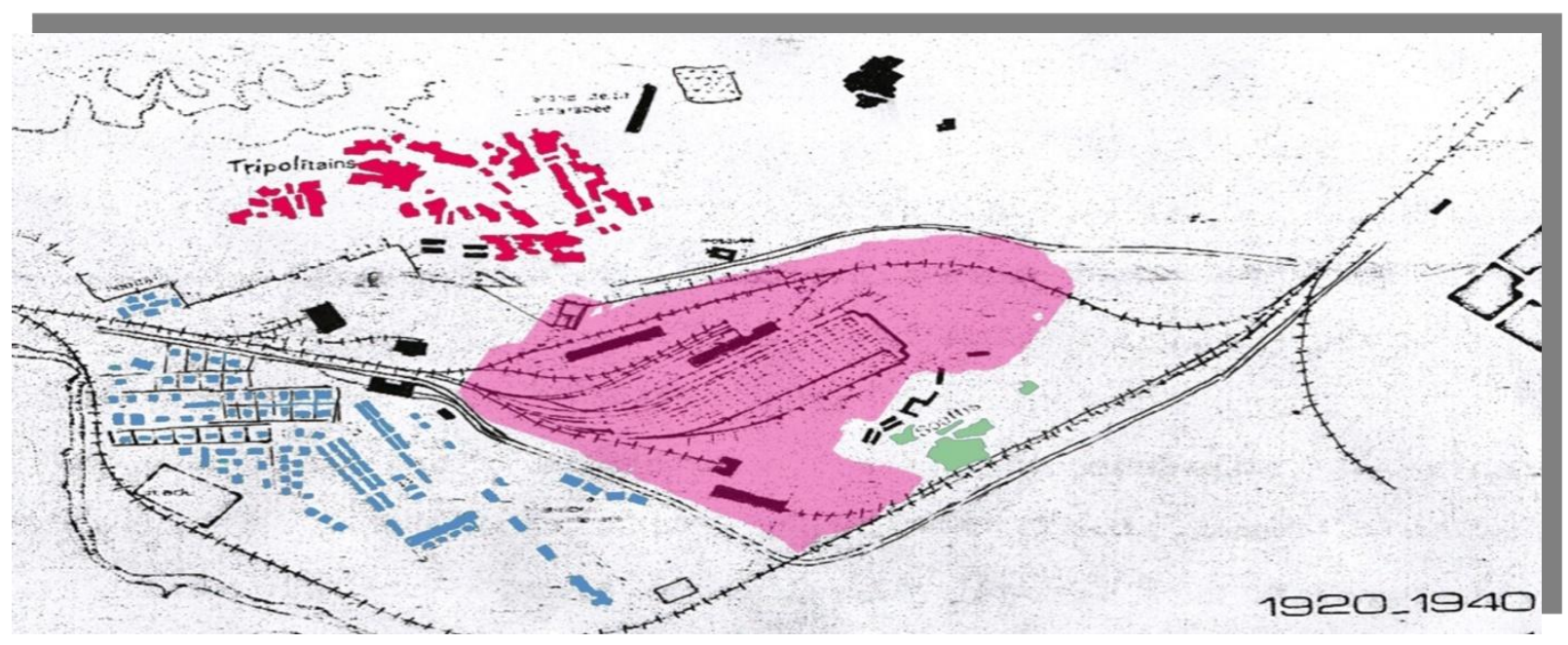

Source: Center data, maps and archives mining, CPGT for the period (1910-1920).

Note 1. The black rectangles and the color Green in map in some way represent: The administration of the mine, the Commissary, the Dispensary, the Post Office, the Church and the Club including the Tennis court, petanque, Cinema Room.

\section{Card 4. Incoming New Maghreb: Urban Expansion, economic and cultural.}

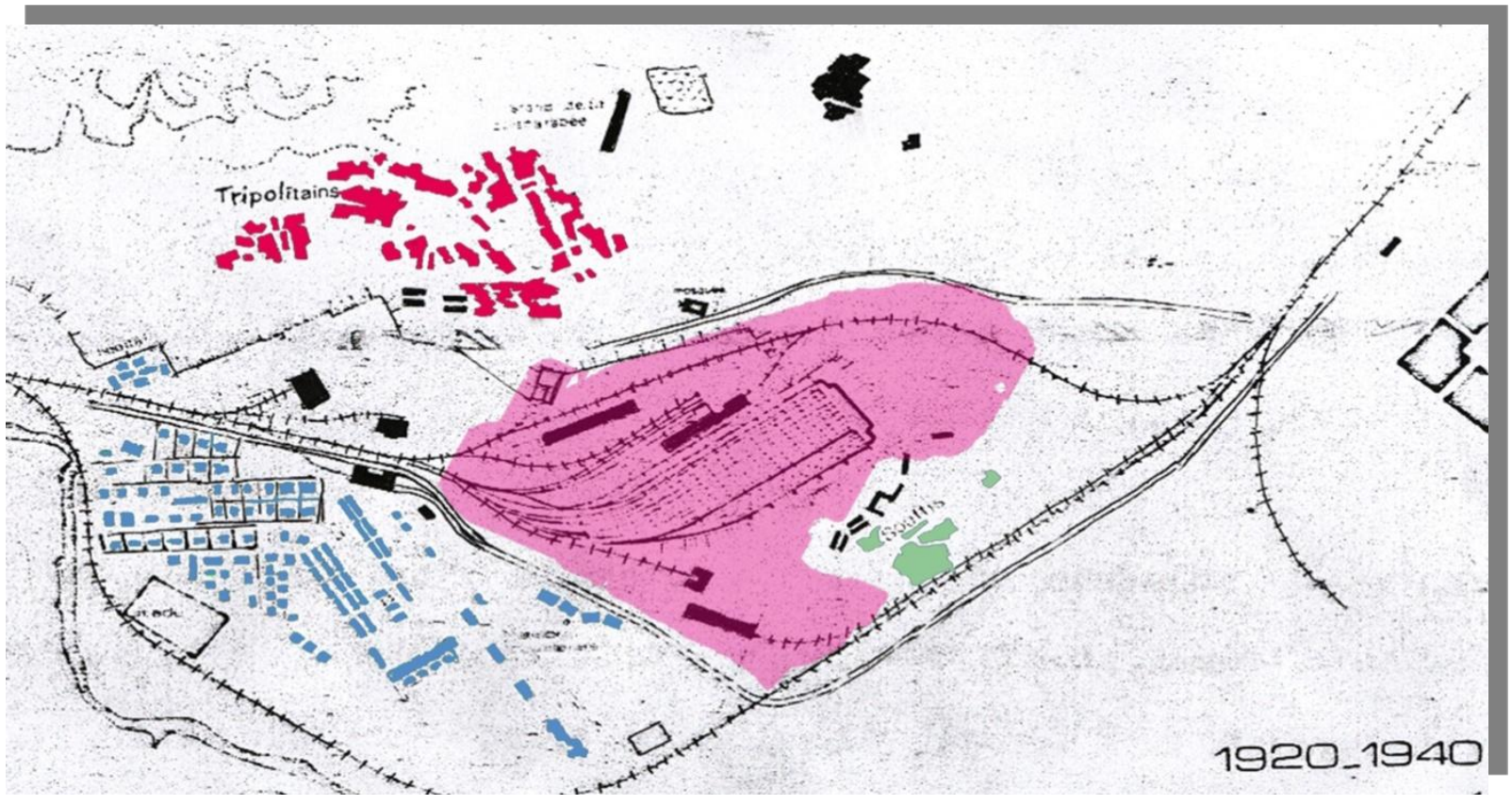

Source: Center data, maps and archives mining, CPGT for the period (1920-1940).

Note 2. The colors red, blue and dark blacks represent the new conglomerates heterogeneous (Moroccan, Algerian, Libyans) is implanting to round about the Mining Basin Tunisian, enriching the urban fabric and socio-cultural and economic of the mining region (SMALL PARIS). 


\section{Card 5. Multicolored Urban Landscape: French \& Italian the Kabyles Algerians and} Moroccans: socio-cultural and economic diversification.

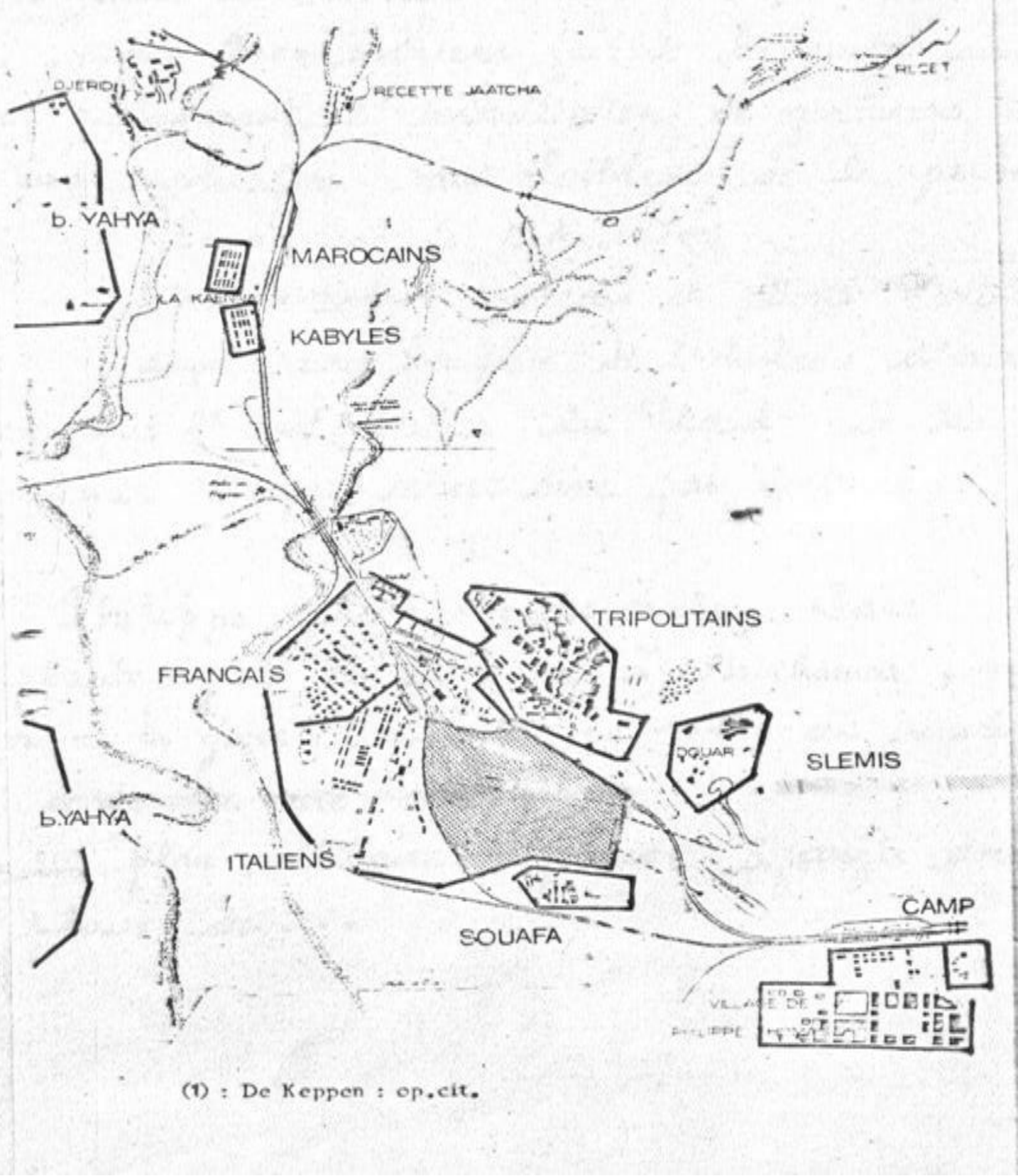

Source: Center data, maps and archives mining, CPGT for the period (1920-1940).

Note 3.The colors red, blue and dark blacks represent the new conglomerates heterogeneous (Moroccan, Algerian, Libyans) is implanting to round about the Mining Basin Tunisian, enriching the urban fabric and socio-cultural and economic of the mining region (SMALL PARIS). 